\title{
Equitable Cities: Spatial Pattern and Accessibility of Public Secondary Schools in Ogbomoso North, Nigeria.
}

\author{
*Akindele O. Akin, *Adigun F. O and *OlatundeRazaq \\ *Department of Urban and Regional Planning, LadokeAkintola University of \\ Technology, Ogbomoso. \\ oaakindele37@lautech.edu.ng \\ +2348038093456
}

\begin{abstract}
Against the background of uncontrolled urbanization, the sprawling slum formation and the need for equitable distribution of basic facilities in cities, this paper analyses the spatial pattern of public secondary schools in Ogbomoso North local government with the view to suggest necessary means of improving urban access to basic facilities and services. The inventory of the location of the public secondary schools was taken;spatial analysis and conformity with the acceptable service radius were appraised. Household survey was conducted on 526 respondents using a structured questionnaire administered through multistage sampling system.Likert method was used to scale the ordinal data, making them amenable to parametric testing. Nearest neighbor analysis technique was used to explain the spatial pattern of public secondary schools in the study area using Geographic Information System (GIS). Buffering analysis was also done to show the catchment area of the schools and explain the distance accessibility to them viz-a-viz the acceptable service radii. With the nearest neighbor index of 0.57 , meaning that the schools are relatively Buffering analysis showed that $47.9 \%$ of Ogbomoso North Local Government is not served with a public secondary school within $1600 \mathrm{~m}$ radius. The study thus recommends the preparation of a functional master plan that will be sensitive to ergonomic space usage and equitable city development.
\end{abstract}

Keywords: Equitable cities, sustainable growth, Spatial Pattern, School, Nigeria

\section{Introduction}

The relegation of urban spatial interaction at the wake of yet increasing urbanization has continued to trigger myriads of environmental problems. The resulting high level sprawl development (Rodrigue, 2013; Bununu, 2011; FON, 2001)etched in the loss of open space, urban decay, unsightly urban developments, urban air and water pollution, traffic congestion (Aderamo, 2012), encroachment into agricultural land (Adeboyejoet al, 2007), increasing 
reliance on automobile (Levine and Grab, 2002), the separation of residences from work, schools, shops, market, worship centers and recreation facilities among others (Kunstlar 1993; 2006; Nechyba and Walsh 2004) aggravates inequalities among the urban regions. To this end, distance to basic activity centers and facilities are today measured by driving time instead of walking time. More time and money is spent on intra-city travels (Koolhaas, 2003). Cities have thus become less livable and sustainable.It therefore begs attention.

Functions of many city parts are being outlived in space and time (Soja,1980;1996).Cities face service equity issues as they grow rapidly and are unable to satisfy the needs of their increasing population (Chin-Hsien et al, 2009). Suffice to say facility and service adequacy are not only instrumental but are a prerequisite to national growth and development (Reinikka and Svensson, 2002).In the face of economic downturn, a conscious scientific spatial distribution of basic facilities would improve access to the relatively fewer facilities that the Government can provide. City's growth without a corresponding growth in necessary facilities (Egunjobi, 2006), creates longer distances to the city centre,reducing the accessibility to basic facilities such as schools (Oguniyi and Obell, 1988). Older residents are kept within the downtown and younger residents the city suburbs. This creates myriads of undesirable consequences both for the kids and the city at large (Glaeser and Kahn, 2003). In the face of economic downturn, a conscious scientifically based spatial distribution would improve access to the relatively fewer facilities that the Government can provide.

The cyclic growth of urban inequality has been widening the inequality gap even further with every cycle. Thus, the optimization of urban development advantage would become an illusion with the relatively high inequalities among urban regions. Inequality is a major factor for the ingrained urban poverty. In fact a new perspective of urban poverty is framed within the notions of relative deprivation and social exclusion. This is giving birth to new forms of poverty such as: 'infrastructure-poor', 'feminization-poor', 'immigrant poverty', 'vulnerable elderly' and 'youth at risk' (Lopez, 2010). Youth inequalities in cities is etched in the discriminated access to livelihood opportunities such as education, employment, economic related infrastructural facilities; causing and reinforcing other forms of inequalities (UNHabitat, 2008; UNICEF UN Women, 2013; UN-Habitat, 2010). Cities are therefore today rife with invisible borders, splitting it physically, socially, economically and psychologically, causing untold socio-economic, socio-cultural, socio-psychological and other exclusions among urban residents. The gap has continued to widen between the 'haves' and the 'have 
nots'. Developed Cities and countries are fast becoming socially immobile. This makes the tendencies to be even higher among developing nations for their cities to grow more unequal. School-home propinquity travel distance for pupils is usually a strong factor for placing schools (Perry, 1929). Schools are points of specific activity, which requires selection of specific site and collaborative effort through: conformance with future need; centrality to catchment area, vehicular access to school site by road, adequate land for proposed and future planned use, proximity of site to public activities such as electricity and water, economical, conformance to surrounding land uses, safety of children and reasonably leveled site.Against the tenets of the neighborhood concept (Perry,1929) kids are no longer able to work to their schools on their own. Many of these students who take to the difficult choice of walking to school on daily basis are today exposed to thorough traffic on their ways to school. Some parents who can afford it and whose job permits it convey their wards with their cars. Some others rely on the exorbitant use of the school buses. As a result, several vehicular and bike accidents involving school children has been recorded.

What then is the spatial pattern of public secondary school location in the city?Are secondary schools more accessible to some areas more than others and is the accessibility with moderate effort? Can we say that the existing planning standards in terms of service radius for public secondary schools are complied with? Are these standards practicable and acceptable to residents in the city? The answers to these and allied questions is the thesis of this paper. Thus this paper analyses the spatial pattern of public secondary schools in Ogbomoso North local government with the view to suggest necessary means of improving its standards for better future equitable city.

\section{Research Methodology}

This study used both the primary and secondary data. After adequate consultation with both published and unpublished relevant literature materials,reconnaissance survey was done. Inventory of the 21 public secondary schools in Ogbomoso North Local Government Area were conducted by taking and geo-referencing their coordinates with the use of GPS and raster maps. This enables the comparison of the observations with the ideal service radii. Household survey was conducted by administering a questionnaire on 526 respondents using a multistage sampling procedure. Ordinal data were scaled reminiscent of the Likert scaling method, making them amenable to parametric testing. Nearest neighbor analysis technique was used to explain the spatial pattern of public secondary schools in the study area using 
GIS.Buffering analysis was also done to show the catchment area of the schools and explain the distance accessibility to them viz-a-vizthe acceptable service radii.

\section{Background to the Study Area}

It becomes necessary to explain the characteristics of the study area so as to put the study in the proper perspective and context.Ogbomoso is the second largest city in Oyo state, in southwestern Nigeria, West Africa. Ogbomoso North Local Government area contains more of a relatively newer area of the larger OgbomosoTownship. Although, there are core areas in the local government, most of the lager city expansion takes place on its northern part.

Similar to most other traditional Yoruba towns in Nigeria, the city of Ogbomoso expanded from its nucleus, which is the palace or its center. This explains why most of the public schools seem to be concentrated within the core area. The establishments of a University in the northern part of the town some two and half decades ago is the most probable reason that the focus of the city expansion has been towards the Northern part of the city.

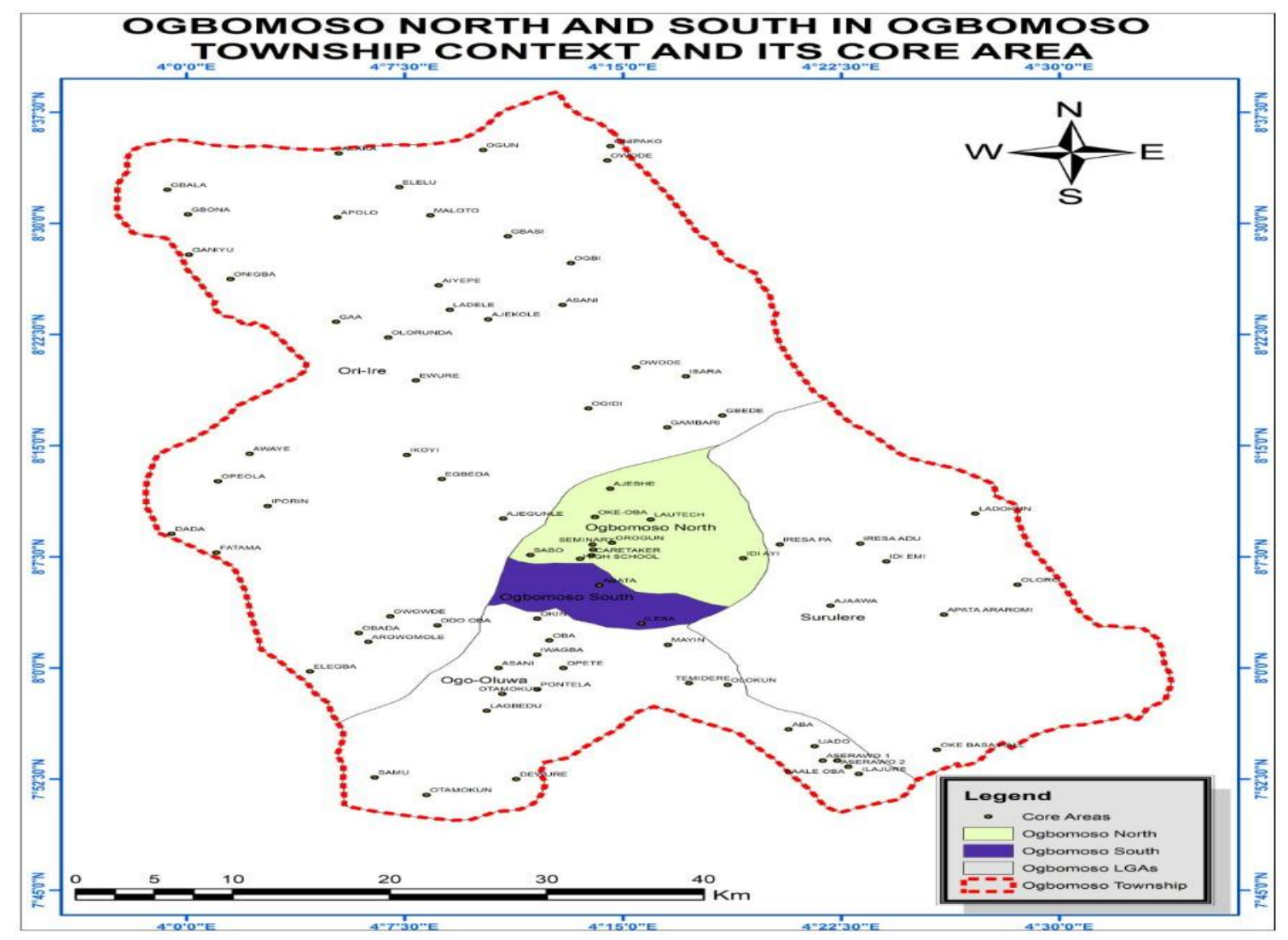

Source: Adapted fromOgbomoso Imagery, 2016

\section{Equitable Distribution of Facilities through Spatial Planning}

There has been a plethora of views on spatial equity (World Bank, 2006). Equality of distance and physical access (Smith, 1994; Talen and Anselin, 1998; Kinman, 1999; 
Ogryczak, 2000), have dominated such views in recent time. Spatial equity implies that there is an even distribution of services in relation to the needs, and preferences of areas in the city. The idea of spatial equity connotes equal treatment and emphasizes the relationship of equity and location (UN-Habitat WUF7, 2014). It is opined here that equality should be interpreted in form of access to opportunity for example equitable transportation should mean that everyone could drive comfortably not necessarily that equal length or width of roads should be available to all.Everyone should be able to do basic things required for their living but not necessarily in the same quantity but some good quantities based on real population distribution; factoring age brackets, socio-economic classes and needs and resources available into consideration. A compromise between distance and economic tradeoffs may be a plausible guide towards meaningful placing of things in the city.

Satisfying all criteria may be difficult. Prioritizing them would help and, depending on the physical and social situation in the concerned community; geographic centrality should be married with socially desirable attributes while safety and convenience of the user in terms of walking distance among others should top the order of preference.It is believed that a circular distribution rather than oblong location of facilities is more appropriate for school facilities. The level of accessibility should be considered when distributing facilities which means that, facilities should be made easily accessible to its potential users. Priorities should be given to facilities spacing and accessibility (Onyele, 2000; Adeniji, 2005) this effectively guarantees higher livability in cities. Maximization of public facility usage and efficiency is grossly dependent on the spatial appropriation etched in the conscious and cautious placing of such facilities. Hence, the ideal is to minimize aggregate travel for the concerned population in order to access the facilities. As population is rarely evenly distributed on the landscape, the problems arise as to whether to provide one large facility scattered over the landscape. The smaller the aggregate travels, the more efficient the facility's location and the easier it is for potential users to reach the locations.

A network of schools neither too far apart nor too near to each other. Apart from constraints of topography and road network, the other factors that might militate against specifying location standards for public facility such as school is the fact that variation in density of the dispersed population in an area may make it difficult to obtain the threshold population which is necessary for the establishment of a particular type of facility within its range of service. It is therefore difficult to lay down specific standards with respect to location. 


\section{Discussion of Findings}

Understanding spatial equity of secondary schools in the area requires their inventory. This necessitates the taking of coordinates of the schools using the global positioning system. The current google earth raster imagery of the study area was used to locate the coordinates of the schools and through the use of ArcMap, a composite map was producedto show the distribution of the public schools. The spatial pattern of the schools was analyzed using the nearest neighbor analysis. Further to this explanation is the buffering operation to depict the level of equitable distribution of the schools

\section{Inventory of Public Secondary School in Ogbomoso NLGA}

It is worthy of note at this outset that there is a higher incidence of residents $(71.8 \%)$ in the suburbs who has school age children while fewer families (18.4\%) has school age children. This connotes that more families at the periphery requires access to secondary schools than their downtown counterparts. Reckoning with the prevailing land tenure systems in most traditional cities, newer families tend to find themselves at the peripheral areas and the older families at the downtown. The reason is a blend of choice (67.2\%) and space availability for new buildings (79.8\%) that fits the taste and fashion of the new and modern families.

\section{Figure 1: Inventory of Public Secondary School in Ogbomoso NLGA}

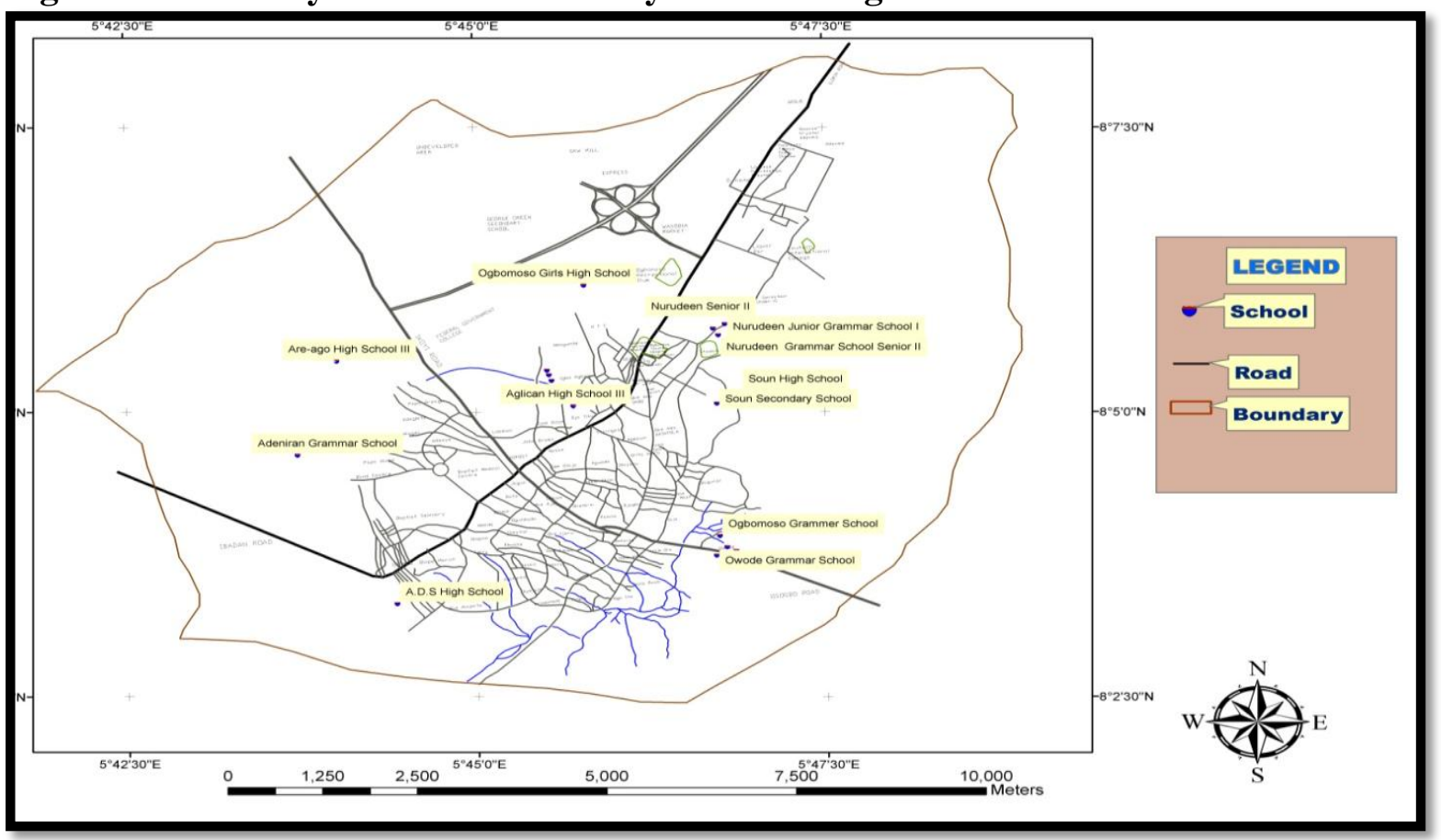

Source: Author's field wok, 2016.

There are 21 public secondary schools in the Local Government area as shown on Fig 1. It was observed that while some of the public secondary schools are very close to each other some or some groups are distant. The implication of this is that the locations of the schools 
were without any conscious scientific considerations but by chance. Many of these secondary schools spread along the divide between the North and the South local government areas; suggesting a wide gap between the public facility and the peripheral residents. This is indicative of poor accessibility of many peripheral residents; especially Ogbomoso North residents to public secondary schools in the area. The wider the expansion in each of the local Government, the poorer the accessibility to the secondary schools become.

\section{Nearest Neighbor Analysis}

It may also be observed form a cursory glance on the figure 1 that the location of the schools did not follow a specific pattern. While they look scattered on the map, the schools may be grouped into fewer clusters, suggesting that the accessibility may be relatively poor even among the core area residents. This is because even a good expanse within the built up areas

\section{Figure 2: Nearest Neighbor Analysis.}

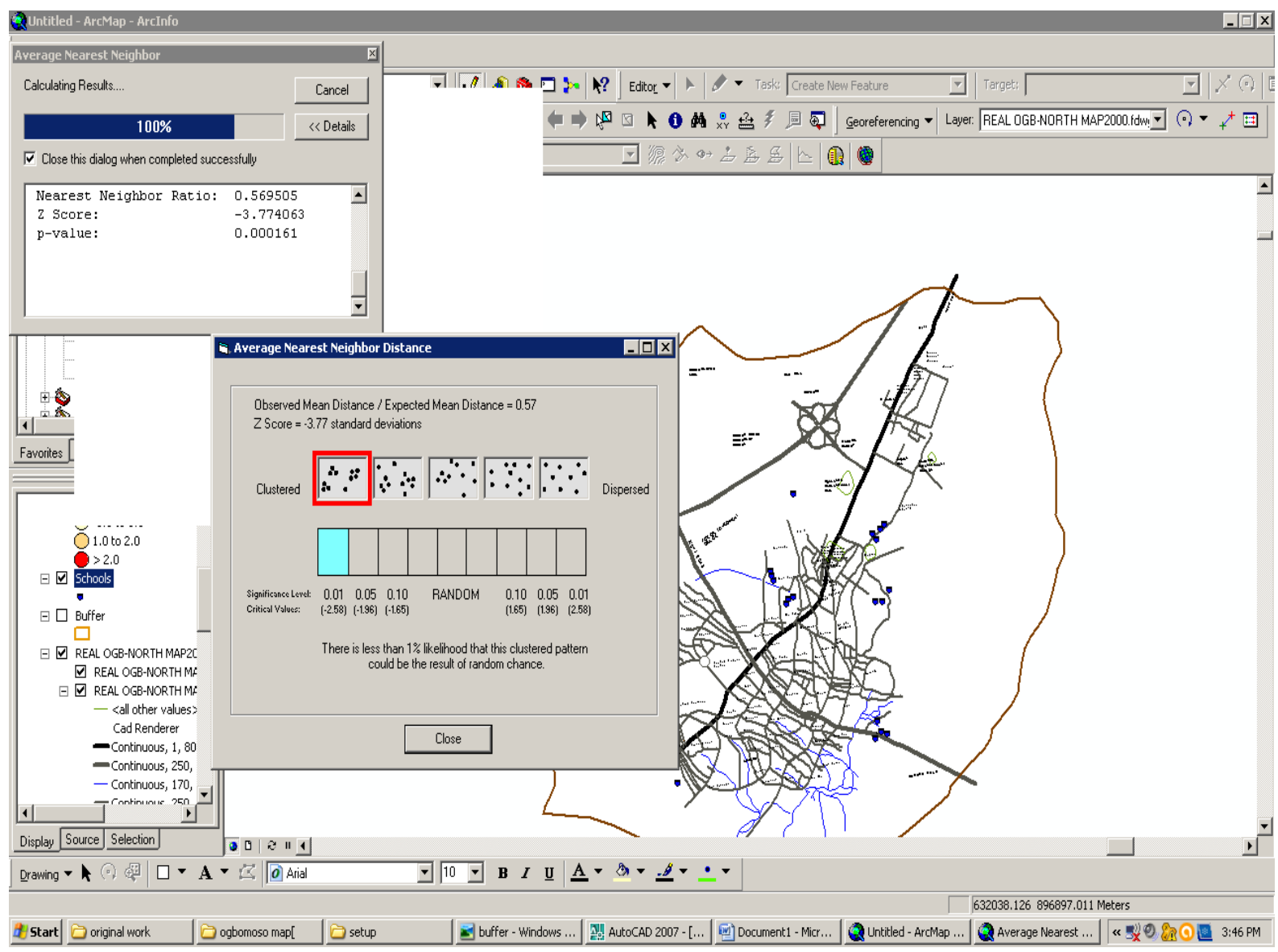

Source: Author's field wok, 2016.

is void of schools. A further analysis therefore becomes necessary to explain the spatial pattern of the schools. In this study, a nearest neighbor analysis was computed. Nearest neighbor analysis was used to examine the distances between each point and the closest point 
to it, and then compares these with expected values for a random sample of points from a complete spatial randomness (CSR) pattern. The values of nearest neighbor index (NNI) ranges between two theoretical extremes of 0 and 2.1491. When all the points in a pattern fall at the same location, they are said to be clustered because the distance between them tends to zero. The closer a nearest neighbor index (NNI) gets to 1 , the more randomly spaced the points are. Perfectly uniformly spaced points has NNI=2.1491.

Using ArcMap 9.3, the nearest neighbor index of the public secondary schools was computed to determine their spatial distribution (Figure 2). The nearest neighbor ratio is 0.57 , this tends to zero and implies that the schools are relatively clusteredto understand the relative incidence of the clustering; the $\mathrm{Z}$-scores for the $\mathrm{Rn}$ values were computed.The calculated $\mathrm{Z}$ score was -3.77 (tending to the maximum value of -4 deviations below the mean). Thishigh negative value indicates that school should be considered to be relatively highly clustered. Summarily, the schools are not evenly distributed but seem to have clustered in groups across the study area. This implies that considering the total land area of the local Government. Most of the schools locate close to one another around the center (core area of the town) with high propensity to reduce access to many residents especially the suburbia residents.

The consequences of this on the livability of the city can be many. The cost of schooling becomes higher with added transportation costs to be bore by the parents and guardian of the students. On the other hand, for the students whose parents may not be able to afford daily transportation fare, wards are forced into daily long walks to school and mostly on highways; none of which are designed to accommodate pedestrians or cyclists. This is not without attendant problems. For instance, $71.7 \%$ of the respondents agreed that road accidents are common and have claimed lives of very many secondary school students. Students therefore get late to school (49.7\%) and take unnecessary time to adjust into learning in their respective classes, which negatively affects the performance $(57.1 \%)$ of both the teachers and the students. The long distance between schools and homes has a high propensity to prevent proper monitoring $(52.3 \%)$ of wards by their parents or guardian

\section{Space Standard and Service Radii Adequacy of the School in Ogbomoso NLG}

Equitable distribution is a function of adherence to codes and standards that are believed to be providing the minimum convenience to the users of secondary school. The question to be answered here is: what is the maximum distance that secondary school age children are ideally prepared to walk between home and school? When such distances are more than what 
is believed to be the ideal then, the school is physically less accessible to such student.

Literature has it that the maximum distance that should be walked by secondary student is $1600 \mathrm{~m}$ (Obateru, 2001). This $1600 \mathrm{~m}$ criterion was used.However in the study, the perspective of the students differed.Most of the student $(68.3 \%)$ would take bike for such distance except they have no financial ability. Most of the student studied (91.8\%) are not prepared to walk more than $500 \mathrm{~m}$. To this end, a buffering analysis was performed to explain equitable distribution of the school. This explains the percentage of families whose children can access the schools within a maximum distance of $1600 \mathrm{~m}$

\section{FIGURE 3: Buffer Operation to show the Catchment Area}

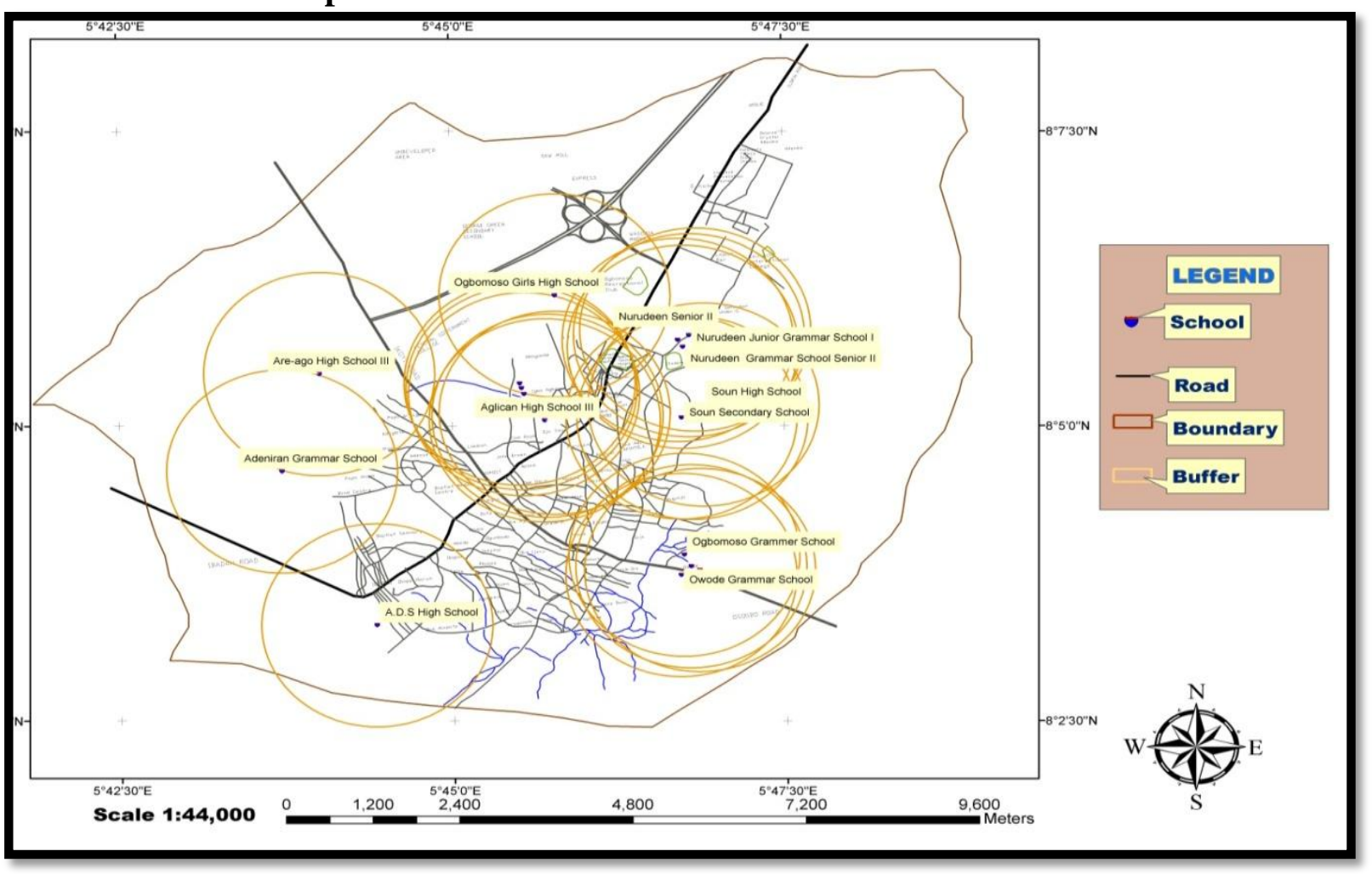

Source: Author's device, 2016.

Buffering analysis is a spatial function in which a zone of interest is created around a given feature or object. It is used to show the extent of coverage of an activity. In this project, a buffering distance of $1600 \mathrm{~m}$ was created around the public secondary schools to determine the catchment area served by the schools based on the aforementioned criterion. This was then used to determine the areas being served and those that are not. The area that is not covered by the buffering is indicating that the student residing in such area will travel a longer distance before getting to school. Buffering analysis showed that $47.9 \%$ of Ogbomoso 
North Local Government is not served with a public secondary school within $1600 \mathrm{~m}$ radius.

Again because most of the secondary school age students (67.9\%) reside outside the downtown $59.4 \%$ of the students claimed to travel more than $1600 \mathrm{~m}$ to their schools. The higher incidence of students who walk longer distances may also be due to choice of school. Some students or their parents for various reasons prefer a school that is not the closest to their homes. Gender sensitive schools such as boys' school, or girls' school would also attract students from far and near without considerations for maximum tolerable distances.

\section{Conclusion}

The studyanalyzed the spatial pattern and accessibility of public secondary school in Ogbomoso north local government. The problems facing secondary school students in their quest to attend their schools were also discussed from spatial equity point of view. Geographical information system was used to analyze the spatial distribution and its ability to combine such data with geometric data to give information of high accuracy.It was therefore observed that there is need to review the locations of the public secondary schools in Ogbomoso. As the population increases due to urbanization it as drastically affects the system of education.

\section{Recommendations}

Equitable cities will be practically unachievable without conscious planning efforts. Suffice to say that most cities in Nigeria lack functional master plans, facility provision are not being synchronized with spatial organization by the same Government. A policy option here is that there should be a meaningful overlap between Governmental agencies who are concerned with providing infrastructures and other physical development and city planning agency. Political interest to providing certain infrastructures should be sensitive to plans which have been made with conscious scientific efforts. This again magnifies the importance of the preparation of functional master plans. In the study area, there is no functional master plan that is guiding development. It is advised that one should be prepared and with sensitivity to equitable city development.

Earlier studies in the same area have predicted that the population and land area expansion of Ogbomoso may double in the next four decades (Adeboyejoet al, 2007). It is therefore advised that spaces should be created to accommodate more elementary and secondary schools bearing on the mind the comfortable walking distance to prospective homes of users. Ergonomic space usage is hereby advocated. This is in that composite spaces may be so configured for multiple and maximal use through the grouping of similar or compatible uses 
which in this case may be infrastructural facilities. This would ensure equal access to many

facilities and therby moving the cities forward towards equitable city development.

\section{References}

Adeniji (2005): Effort Made Towards the Realization of Spatial Location of Various Education Facilities in the CountryCalabar. Rapid Educational Publisher Ltd.

Adeboyejo A. T, AboladeOlajoke, Abodunrin F. O and Jelili M. O (2007); A predictive modelling of Urban Expansion and Implications for Sustenance in Peri-Urban Areas of Ogbomoso.A proceedings of the $5^{\text {th }}$ Union of African Population Conference UAPS on the emerging Issues on Population and Development in Africa, Arusha, Tanzania

Bununu, Aliyu, Yakubu (2011): "Analysis of the pattern and Urban Management Implications of sprawl in Kaduna Metropolis Nigeria". Unpublished Dissertation Submitted to the Department of Urban and Regional planning. Ahmadu Bello University, Zaria Nigeria.

Chin-Hsien Liao, Chang Hsueh-Sheng and Ko-Wan Tsou (2009); Explore the Spatial Equity of urban Public Facility Allocation based on Sustainable Development Viewpoint. A proceeding of REAL CORP Conference, Tagungsband, Taiwan, 22-29 April, 2009.http://www.corp.at pp137-145

EgunjobiLayi (2006) Formulation and Implementation of Urban Environmental

Strategy.In: Tunde Agbola (ed) (2006) "Environmental Planning and Management:

Concepts and Application to Nigeria". Ibadan: Counstellation Book. Nigeria.

Eyenghe Tari, Ibama Brown and WochaChikagbum (2015); Assessment of the Location and

Availability of Public Facilities and Services in Port-Harcourt Metropolis in Rivers

State, Nigeria.International Journal of Scientific and Technological Research, Vol 4 Issue 6

Federation of Ontario Nationalist (2001): Urban Sprawl in Ontario and hot to spot it. Southern Ontario City.

Glaeser, Edward and Matthew Kahn.(2003) "Sprawl and Urban Growth.NBER Working Paper No. W9733.

Kinman, E L (1999). Evaluating health services equity at a primary care clinic in Chilimarca.

Bolivia Social Science \& Medicine 49(5), 663-678

Koolhaas R (1995); Whatever Happened to Urbanism? In: Koolhaas R and Mau B (1995) (Eds) S.M.L.X.L Monacelli, New York

Kunstler James Howard (1993); The Geography of Nowhere: The Rise and Decline of American Manmade Landscape. New York: Simon and Schuster

Lóez Moreno Eduardo (2010) Addressing New Forms of Poverty and Exclusion in Europe,

World and European Sustainable Cities, Insights from EU Research, European Commission.

Nechyba, T. J and Randall P.Walsh (2004): Urban Sprawl. Journal of Economic Perspective- pages 177-200.

Obateru, L.I (2003)“Land subdivisions basic".Penthouse Publication, Visionary publisher Ibadan Nigeria.

Oguniyi, D. And Obell, H.O.N. (1988):Spectrum Social Studies for Junior Secondary Schools, Book2,Ibadan: Spectrum Books Limited

Ogryczak, W (2000) Inequality measures and equitable approach to location problems.European Journal of Operational Research 122, pp.374-391 
Onyele V (2000): Dynamic Institutional Management towards Administrative Competence, Yaba Lagos Sam Orient Publishers.

Oyo State (2010) Assessment Format for Standardization of Schools.Official Gazzette of the Oyo State Ministry of Education.

Perry, C. (1929) TheNeighbourhood Unit (1929) Reprinted Routledge/ Thoemmes, London, 1998, P.25-44.

Smith N (2002); New Globalism, New Urbanism, Gentrification as Global Urban Strategy.Antipode. 34 (3) 427-450

Soja E (1980); The Socio-Spatial Dialectic' Annals, Association of American Geographers 70, 207-225

Soja E (1996); Los Angeles, 1965-1992: The Six Geographies of Urban Restructuring in Scott A. J and Soja E (1996) (Eds); The City Los Angeles and Urban Theory at the End of Twentieth Century. University of California Press, Los Angeles 426-462

Talen, E and Anselin, L (1998). Assessing Spatial Equityan Evaluation of Measures of Accessibility to

Public Playgrounds.Environment and Planning A 30, pp.595-613

UN-Habitat (2008) State of the World's Cities Report 2008/2009: Harmonious Cities, Earthscan, London.

UN-HABITAT, State of Urban Youth Report (2010), Earthscan, London.

UN-Habitat (2012), State of the World's Cities Report 2012/2013: Prosperity of Cities, Earthscan,London

UNICEF, UN Women (2013) Young People and Inequalities, Online Discussions, Global Thematic Consultation on Addressing Inequalities, New York.

UN-Habitat WUF7 (2014); Urban Equity in Development; Cities for Life.World urban Forum Medelin, Colombia. 5-11 April, 2014

World Bank (2006) Equity and Development: World Development Report 2006, Washington. 